This is a preprint of an article submitted for consideration in the Inquiry @ 2005 [copyright Taylor \& Francis]; Inquiry is available online at: www.tandfonline.com http://tandfprod.literatumonline.com/doi/abs/10.1080/00201740500241847

Idealism and the Philosophy of Mind, D'ORO G, Inquiry 48(5):395-412 Oct 2005

Idealism and the Philosophy of Mind ${ }^{1}$

\title{
GIUSEPPINA D'ORO
}

University of Keele, UK

ABSTRACT This paper defends an idealist form of non-reductivism in the philosophy of mind. I refer to it as a kind of conceptual dualism without substance dualism. I contrast this idealist alternative with the two most widespread forms of non-reductivism: multiple realisability functionalism and anomalous monism. I argue first, that functionalism fails to challenge seriously the claim for methodological unity since it is quite comfortable with the idea that it is possible to articulate a descriptive theory of the mind. Second, that as an attempt to graft conceptual mind-body dualism onto a monistic metaphysics, the idealist alternative bears some similarities to anomalous monism, but that it is superior to it because it is not vulnerable to the charge of epiphenomenalism. I conclude that this idealist alternative should be given serious consideration by those who remain unconvinced that a successful defence of the non-reducibility of the mental is compatible with the pursuit of a naturalistic agenda.

Introduction

Contemporary philosophy of mind tends to assume that any attempt to do justice to the autonomy of the mental is philosophically respectable only if it is compatible with the ontology of natural science. Consequently, the two most widespread forms of nonreductivism, i.e. token physicalism and functionalism, either endorse a physicalist ontology (token physicalism) or claim to be compatible with it (functionalism). The goal of this paper is to outline a neglected alternative to non-reductivism in the philosophy of mind modelled on the idealist philosophy of R.G. Collingwood. The ancestry of this argument is Kantian, although Collingwood gives an interesting twist to Kant's attempt to limit the claims of knowledge in order to make room for freedom. I will refer to this neglected alternative as a form of conceptual dualism without substance dualism. As an 
This is a preprint of an article submitted for consideration in the Inquiry @ 2005 [copyright Taylor \& Francis]; Inquiry is available online at: www.tandfonline.com http://tandfprod.literatumonline.com/doi/abs/10.1080/00201740500241847

Idealism and the Philosophy of Mind, D'ORO G, Inquiry 48(5):395-412 Oct 2005

attempt to graft conceptual mind-body dualism onto a monistic metaphysics, this

neglected alternative bears some similarities to Davidson's anomalous monism but differs from it in one important respect. Whereas anomalous monism rests on a layered view of science that prioritises the ontology of natural science, Collingwood's defence of conceptual dualism is based on an argument that has its roots in idealist philosophy. The paper proceeds as follows. I begin by outlining two positions in the philosophy of mind that are allegedly compatible with the thesis of the autonomy of the mental: functionalism and anomalous monism. I then introduce Collingwood's neglected alternative and argue that his version of idealism is better equipped to realise the goals pursued by Davidson. I claim that Davidson's defence of the methodological autonomy of the mental fails because of his commitment to a physicalist metaphysics and that Collingwood's marriage of conceptual idealism and neutral monism offers a much better prospect of success than Davidson's defence of non-reductive physicalism. I conclude by suggesting that the internal inconsistencies in the position of non-reductive physicalism do not, by themselves, provide overwhelming reasons for choosing (reductive) physicalism over (conceptual) idealism and that the idealist alternative in the philosophy of mind should therefore be given serious consideration by those who remain unconvinced that a successful defence of the non-reducibility of the mental to the physical is compatible with the pursuit of a naturalistic agenda. 
This is a preprint of an article submitted for consideration in the Inquiry () 2005 [copyright Taylor \& Francis]; Inquiry is available online at: www.tandfonline.com http://tandfprod.literatumonline.com/doi/abs/10.1080/00201740500241847

Idealism and the Philosophy of Mind, D'ORO G, Inquiry 48(5):395-412 Oct 2005

Much recent philosophy of mind has been concerned with the place of mind in nature.

With the demise of the kind of physicalism advocated by Smart (1959) and Feigl (1958)

and of Ryle's logical behaviourism many philosophers have given up trying to reduce the mental to the physical and have started to find ways of accommodating the mind within a physical world. As a result, although most contemporary philosophers of mind accept the ontology of natural science, many believe physicalism to be compatible with the claim that no reduction of the mental to the physical is possible. The reduction attempted by Smart and Feigl's "type" physicalism was empirical in character: they assumed that vernacular talk about the mental could be reduced, via empirically discoverable laws, to talk about the physical, in the same way in which water was found to be identical with $\mathrm{H}_{2} \mathrm{O}$. Ryle's logical behaviourism, on the other hand, sought to accomplish a semantic reduction of the mental to the behavioural by showing that talk about the mental is a covert way of speaking about the behavioural. The perceived failure of reductivism, whether logical or nomological, led many philosophers to pursue the naturalistic agenda in a subtler way, one that could be seen to do justice to the autonomy of the mental. In particular reductivism has come under attack from two different fronts. On the one hand, following Putnam (1975), functionalists have endorsed the multiple realisability thesis according to which mental phenomena can be realised in different kinds of physical systems. Functionalism was thought to deliver a blow to reductive physicalism insofar as it opened up the possibility that different kinds of physical organisms could instantiate the same kind of mental phenomena and consequently that mental types may not be coextensive with physical kinds. ${ }^{2}$ On the other hand, following Davidson (1980), 
This is a preprint of an article submitted for consideration in the Inquiry () 2005 [copyright Taylor \& Francis]; Inquiry is available online at: www.tandfonline.com http://tandfprod.literatumonline.com/doi/abs/10.1080/00201740500241847

Idealism and the Philosophy of Mind, D'ORO G, Inquiry 48(5):395-412 Oct 2005

supervenience theorists have argued for the autonomy of the mental on the grounds that the sciences of mind, unlike those of nature, are intrinsically normative. Although both functionalism and anomalous monism accept token rather than type physicalism and claim, for this reason, to endorse a form of non-reductive physicalism, their respective defences of the autonomy of the mental have very different motivations.

Functionalists view mental phenomena as the intermediary link between environmental stimuli and behavioural responses of a given kind and clearly regard such phenomena as the kind of things that are susceptible to empirical investigation. However, they also want to enable sciences such as psychology to articulate explanatory hypotheses that employ their own vocabulary and concepts, concepts such as that of pain rather than that of $\mathrm{C}$ fibres or the firing of neurons. Functionalists, in other words, do not question the possibility of articulating an empirical theory of the mind; they simply want to formulate explanatory hypotheses that use the vocabulary of psychology rather than that of physics or neuroscience. Davidson's anomalous monism, by contrast, is inspired by the problem raised by Kant's antinomy of freedom and determinism: how can we reconcile the claims of freedom with those of nature? Kant proffered transcendental idealism as an answer. He regarded causes as constitutive of our empirical knowledge of nature rather than as something metaphysically real, thereby leaving open the possibility that things as they are in themselves may be governed by the causality of reason: he limited the claims of knowledge to explain how freedom is possible. Davidson seeks to answer the Kantian antinomy not by limiting the explanatory framework of natural science exclusively to phenomena, but by wedding a metaphysical commitment to 
This is a preprint of an article submitted for consideration in the Inquiry @ 2005 [copyright Taylor \& Francis]; Inquiry is available online at: www.tandfonline.com http://tandfprod.literatumonline.com/doi/abs/10.1080/00201740500241847

Idealism and the Philosophy of Mind, D'ORO G, Inquiry 48(5):395-412 Oct 2005

physicalism with a defence of the methodological autonomy of the mental. Both functionalists, who believe in physical multirealisability, and anomalous monists like Davidson, have endorsed token rather than type physicalism, i.e. the claim that whereas all mental phenomena are physically instantiated, there are no empirical laws to bridge the two domains. In other words, they have embraced physicalism whilst rejecting reductivism. Their motivation, however, is profoundly different. Functionalists are quite comfortable with the claim that it is possible to articulate a descriptive theory of the mind: functionalism propounds an empirical theory of the mind articulated in terms of the vocabulary of vernacular psychology. Anomalous monism, by contrast, denies that an empirical science of the mind is possible by appealing to the Kantian insight that the domain of the mental has a normative dimension that is completely absent from the physical. The autonomy that Davidson seeks to defend, therefore, is a much stronger kind of autonomy. It is not simply the case that the vocabulary of natural science and that of common sense psychology are different, as functionalists claim: the mind/matter distinction, for Davidson, as indeed for Kant, maps onto the is/ought divide. The difference between folk psychology and neuroscience is therefore not just one of vocabulary. It is a methodological difference.

To be sure, Davidson provides a rather unkantian answer to a Kantian problem. Kant acknowledged that rational considerations "determine" actions in a very different sense from that in which empirical laws "determine" the occurrence of events in nature. The former prescribe a course of action, whereas the latter describe the course of events. Kant thought that the claims of theoretical as well as those of practical reason could be 
This is a preprint of an article submitted for consideration in the Inquiry @ 2005 [copyright Taylor \& Francis]; Inquiry is available online at: www.tandfonline.com http://tandfprod.literatumonline.com/doi/abs/10.1080/00201740500241847

Idealism and the Philosophy of Mind, D'ORO G, Inquiry 48(5):395-412 Oct 2005

vindicated by keeping the domain of reasons and that of causes quite separate from one another. Hence, in the Groundwork, he sought to avoid what have become known as the problems of downward mental causation and of explanatory exclusion by refusing to account for how psychophysical interactionism is possible and by arguing instead that the possibility of freedom rests on our ability to conceive of ourselves as members of an intelligible world. Kant acknowledged that the problems of downward mental causation and of explanatory exclusion arise from the demand that reasons should be causally efficacious over and above being rationally compelling and sought to avoid such problems by distinguishing between the phenomenal and the noumenal or intelligible realm. This separation, for Kant, is not a straightforwardly metaphysical one. A different ontology must ${ }^{3}$ be presupposed in order for practical reason to be possible, but the claim that there is an intelligible world is a postulate of reason, not a metaphysical fact of the matter.

Davidson, like Kant, acknowledges that there are fundamental methodological differences between the mental and the physical domains but openly declares his allegiance to the one and only ontology, that of natural science, and endeavours to defend the methodological autonomy of the mental within the constraints of a physicalist ontology. Whereas Kant sought to defend the autonomy of the mental within the framework of a metaphysics of experience, Davidson seeks to defend the autonomy of the mental within the framework of a physicalist metaphysics. Davidson's anomalous monism therefore seeks to retain Kant's methodological dualism whilst jettisoning his transcendental idealism. Kant's transcendental idealism barred the possibility of 
This is a preprint of an article submitted for consideration in the Inquiry () 2005 [copyright Taylor \& Francis]; Inquiry is available online at: www.tandfonline.com http://tandfprod.literatumonline.com/doi/abs/10.1080/00201740500241847

Idealism and the Philosophy of Mind, D'ORO G, Inquiry 48(5):395-412 Oct 2005

answering metaphysical questions about the ultimate structure of reality. Davidson by contrast begins with a metaphysical commitment to the ontology of natural science and then grafts methodological dualism onto it. From this metaphysical platform Davidson proceeds to answer the objection that the methodological autonomy of the mental threatens the completeness of physical explanations by claiming that mental phenomena can indeed cause physical ones but only in so far as they are brought under a physical description.

In sum, the main challenge to reductivism has come either from functionalists who have endorsed the multiple realisability thesis or from supervenience theorists inspired by Davidson's anomalous monism. Functionalism defends the autonomy of the mental only in the very minimal sense that it permits sciences such as psychology to formulate explanatory hypotheses that employ common sense psychological vocabulary. But it does not challenge the idea of methodological unity since it is completely at ease with the view that it is the task of a science of mind to investigate empirical correlations between environmental inputs, mental phenomena and behavioural outputs. ${ }^{4}$ It is Davidson who has challenged the idea of methodological unity ${ }^{5}$ by arguing that the distinction between the mental and the physical coincides with the is/ought distinction. Anomalous monism's argument against reductivism is that since the mind/matter distinction cuts across the is/ought divide, to reduce the mental to the physical by means of bridge laws would be equivalent to reducing the normative to the descriptive, and that, as Davidson says, "there is good reason to believe it cannot be done". ${ }^{6}$ Many have remained unconvinced by Davidson's attempt to graft methodological dualism onto the 
This is a preprint of an article submitted for consideration in the Inquiry @ 2005 [copyright Taylor \& Francis]; Inquiry is available online at: www.tandfonline.com http://tandfprod.literatumonline.com/doi/abs/10.1080/00201740500241847

Idealism and the Philosophy of Mind, D'ORO G, Inquiry 48(5):395-412 Oct 2005

ontology of natural science. It has been pointed out, for instance, that Davidson fails to meet the charge of epiphenomenalism and that his attempt to accommodate the thesis of the autonomy of the mental within a naturalistic agenda cannot succeed. Such concerns arise primarily from the consideration that if reasons do no explanatory work at the relevant level, i.e. the metaphysical level, they remain causally inert. Davidson's anomalous monism, in other words, remains trapped between the Scylla of epiphenomenalism and the Charybdis of explanatory exclusion: reasons either remain causally inert qua reasons or they are causally efficacious qua reasons, in which case they threaten the claim of physics to provide a complete explanation of reality. Hence they are either epiphenomenal or incompatible with the metaphysics of natural science. ${ }^{7}$ But I will return to these objections later in section three. My task now is to articulate what I have referred to as a neglected alternative to non-reductivism. This alternative, which I argue is aptly represented by the philosophy of R.G. Collingwood, not only revisits the Kantian question, as indeed Davidson does, but also seeks to provide an answer which is ultimately much truer to the spirit of Kantian idealism.

\section{II}

Like Davidson, Collingwood thinks the mind-body problem is one that arises from the relationship between normative and descriptive discourses. ${ }^{8}$ To defend the autonomy of the mental is therefore not merely to articulate a causal theory of the mind in the vocabulary of folk psychology rather than that of neurophysiology, as functionalism would have it; it is to argue for the existence of fundamental methodological differences 
This is a preprint of an article submitted for consideration in the Inquiry @ 2005 [copyright Taylor \& Francis]; Inquiry is available online at: www.tandfonline.com http://tandfprod.literatumonline.com/doi/abs/10.1080/00201740500241847

Idealism and the Philosophy of Mind, D'ORO G, Inquiry 48(5):395-412 Oct 2005

between the sciences of nature and the sciences of mind. Unlike Davidson, however, Collingwood does not wish to characterise the relationship between the physical and the mental as a relationship of supervenience. This is because he believes there is a deeper link between methodological and ontological questions than Davidson allows. For Collingwood the method of a science determines its subject matter or "regional ontology". ${ }^{9}$ Hence the science of mind is concerned with actions because it investigates what exists as a manifestation of rational processes. The sciences of nature, by contrast, are concerned with events because they describe what is as a manifestation of natural laws. To declare one's allegiance to physicalist ontology unconditionally or independently of the set of heuristic principles which guide the sciences of nature, as Davidson does, is mistakenly to grant metaphysical status to what is merely the subject matter of natural science. Physicalism, for Collingwood, is not the one and only ontology, but simply the regional ontology of natural science. Thus Collingwood not only argues for the non-reducibility of normative to descriptive claims, as Davidson does; he also rejects the view that there is a level of explanation that has ontological priority and with it the layered view of science that underpins the supervenience/subvenience relation. ${ }^{10}$

The claim that for Collingwood there is deeper link between methodology and ontology should be assessed with due care: Collingwood is not advocating a return to Cartesian or substance dualism. He merely claims that there is a link between one's methodology and one's ontology in the sense that method determines subject matter. There is, for Collingwood, no link between methodology and metaphysics properly speaking because the study of what is or exists (ontology traditionally understood) cannot 
This is a preprint of an article submitted for consideration in the Inquiry @ 2005 [copyright Taylor \& Francis]; Inquiry is available online at: www.tandfonline.com http://tandfprod.literatumonline.com/doi/abs/10.1080/00201740500241847

Idealism and the Philosophy of Mind, D'ORO G, Inquiry 48(5):395-412 Oct 2005

be carried out independently of the investigative goals of different sciences. In other words, whereas it is legitimate to ask what exists for the historian (actions) and what exists for the natural scientist (events), there is no answer to the question about what exists in general, outside the parameters of any specific investigation. Since Collingwood closely links the method of a science to its subject matter, he rules out the possibility that one could address the metaphysical question about what exists independently of the methodological question about how we come to know it.

Collingwood makes this point by claiming that there are three kinds of explanation (he refers to these as three senses of the term "cause"), which correspond to the investigative goals of different sciences. Explanations of actions make use of what he calls causation in sense I. In sense I to cause means to afford a motive. In so far as action explanations make sense of causes in sense I, they establish a teleological connection between the explanans and the explanandum. This is the concept of causation employed in the sciences of mind. Explanations of events which are in one's power to prevent or produce make use of what he refers to as causes in sense II. In sense II causes are like handles. This is the concept of causation used in the practical sciences of nature such as medicine and engineering. Explanations of events that are beyond one's power to prevent or produce make use of a different concept of causation (sense III). This is the sense of causation at work in the theoretical sciences of nature, such as physics. In claiming that explanations in the historical, practical and theoretical sciences of nature make use of three different senses of the term cause, Collingwood is making the point that the three concepts of causation are species of the same genus, i.e. that they are all forms of 
This is a preprint of an article submitted for consideration in the Inquiry @ 2005 [copyright Taylor \& Francis]; Inquiry is available online at: www.tandfonline.com http://tandfprod.literatumonline.com/doi/abs/10.1080/00201740500241847

Idealism and the Philosophy of Mind, D'ORO G, Inquiry 48(5):395-412 Oct 2005

explanation. His interlinking of methodology and ontology entails the view that the distinction between so-called reasons and causes is a distinction between the a priori categories that govern the study of mind and nature respectively, and that the corresponding distinction between rational and causal explanations is a methodological distinction or a distinction between kinds of explanation, not a distinction between explanations that have and do not have ontological or existential import.

This claim is clearly at odds with contemporary orthodoxy in the philosophy of mind. In contemporary debates in the philosophy of mind the question concerning the relationship between what Collingwood calls different senses of the term cause is framed not in answer to a conceptual question (what is the nature of action explanation?) but in answer to a metaphysical concern (can rationalising explanation have ontological import and if so what consequences does this have for the physicalist's claim to causal closure?). It is therefore not uncommon to criticise the methodological discussion of the action/event distinction characteristic of philosophy of social science in the 1950s and $1960 \mathrm{~s}^{11}$ on the grounds that it displays a rather cavalier attitude to metaphysics. Kim, for instance, dismisses attempts that seek to solve the problem of mind-body dualism by arguing for the logical independence of rational and causal explanations as mere "deflationary approaches" or "free lunch" solutions ${ }^{12}$. Crane echoes this criticism by arguing that the debate concerning the possibility of mental causation is a debate about causation, not explanation. For Crane those who claim that scientific and mentalistic explanations do not conflict, because they are logically independent, ${ }^{13}$ simply fail to understand that the question concerning the possibility of mental causation is not a 
This is a preprint of an article submitted for consideration in the Inquiry @ 2005 [copyright Taylor \& Francis]; Inquiry is available online at: www.tandfonline.com http://tandfprod.literatumonline.com/doi/abs/10.1080/00201740500241847

Idealism and the Philosophy of Mind, D'ORO G, Inquiry 48(5):395-412 Oct 2005

methodological question about the logical form of action explanation but a metaphysical question about the possibility of overdetermination by mental and physical causes. ${ }^{14}$ Construed metaphysically, the question "how is mental causation possible?" asks not "what is the logical structure of mentalistic explanations and how do they differ from explanations in natural science?" but "how is causal overdetermination by the mental and the physical possible?"15

Collingwood's approach differs from most contemporary treatments of nonreductivism. The latter, as we have seen, seek to account for the autonomy of the mental within the framework of a naturalistic agenda that requires them to grant special metaphysical status to the kind of explanations employed in natural science. Following Kant's lead, by contrast, Collingwood takes the concepts of action and event to be the $a$ priori categories governing the investigation of mind and nature respectively.

There are, however, a number of important respects in which Collingwood's defence of the autonomy of the mental differs from Kant's and it is important to acknowledge them. Collingwood carries Kant's epistemological reform of metaphysics a step further by denying even the logical possibility of knowing things as they are in themselves. Against Kant's claim that things as they are in themselves could only be known by an intellectus archetypus, Collingwood states that they are not simply unknown to beings which lack the faculty of intellectual intuition, but that they are unknowable in principle. This is what he means by claiming that there can be no science of pure being. Collingwood understands the word "science" in the Latin sense of the term scientia to mean a body of knowledge with a specific method. On this understanding of 
This is a preprint of an article submitted for consideration in the Inquiry @ 2005 [copyright Taylor \& Francis]; Inquiry is available online at: www.tandfonline.com http://tandfprod.literatumonline.com/doi/abs/10.1080/00201740500241847

Idealism and the Philosophy of Mind, D'ORO G, Inquiry 48(5):395-412 Oct 2005

the term there can be no science without a set of presuppositions or methodological assumptions and hence no science of pure being or ontology in the traditional sense of the word. Metaphysics can only take the form of an enquiry into regional ontologies or the heuristic principles governing first order sciences. This radicalisation of Kant's epistemological reform of metaphysics has an important implication. Unlike Kant, Collingwood makes no distinction between the constitutive and regulative uses of reason. The distinction between theoretical and practical reason, for Collingwood, is not a distinction between judgements which possess and judgements which lack objective validity or existential import, but a distinction between logical forms that enable us to individuate particulars either as actions or as events. When we describe an occurrence as an expression of thought we identify it as an action, in the same way in which when we describe an occurrence in causal terms we identify it as an event. Collingwood does not claim that whereas events occur in space and time, actions do not, and consequently that action explanations, unlike event explanations, are mere rationalisations lacking ontological or existential import. Since Collingwood rejects Kant's view that whereas theoretical judgements are constitutive, practical ones are merely regulative, he does not rest his defence of the possibility of practical reason on the claim that action explanations have no application to spatio-temporal particulars and consequently that, if true, could be true only of an intelligible reality. As Collingwood puts it in An Essay on Metaphysics, the different notions of causality that regulate investigations in the sciences of mind and in the practical and theoretical sciences of nature are absolute presuppositions or heuristic principles which cannot be justified empirically by asking whether they fit with what 
This is a preprint of an article submitted for consideration in the Inquiry @ 2005 [copyright Taylor \& Francis]; Inquiry is available online at: www.tandfonline.com http://tandfprod.literatumonline.com/doi/abs/10.1080/00201740500241847

Idealism and the Philosophy of Mind, D'ORO G, Inquiry 48(5):395-412 Oct 2005

exists. Their justification is to be sought in the fact that they make different forms of investigation possible in the first place. The concept of truth and falsity applies only to what he calls relative presuppositions, i.e. presuppositions internal to a given form of enquiry. Hence, for instance, whereas the (relative) presupposition that the cause of malaria is the bite of a mosquito may be either true of false, the (absolute) presupposition that illness may be either prevented or produced by creating or eliminating certain antecedent conditions (causation in sense II) is neither true nor false but a pre-condition for carrying out the form of enquiry within which true or false claims can be advanced.

Collingwood's radicalisation of Kant's epistemological reform of metaphysics thus entails that we can ascribe the concept of action to spatio-temporal particulars in the way in which we can ascribe the concept of event to particular things. We could describe $\mathrm{x}$ either as "the opening of a window" with reference to a motive (for example, letting air in) or as the movement of the biceps and both descriptions could be true of the same particular. The reason why action and event explanations could be true of the same particulars is that the concepts of action and of event are not class or empirical concepts which carve out a part of reality but higher level concepts that determine a priori what kind of reality one is talking about. In other words, the concepts of action and of event, for Collingwood, do not stand to one another as the concepts of red and blue. Blue and red are species of the empirical genus colour. As species of an empirical genus they carve out a part of reality and, as such, cannot coincide in their instances. What is red cannot be blue and so on. The description of what occurs as either an action or as an event, by contrast, does not rest on an empirical classification since the ability to distinguish 
This is a preprint of an article submitted for consideration in the Inquiry @ 2005 [copyright Taylor \& Francis]; Inquiry is available online at: www.tandfonline.com http://tandfprod.literatumonline.com/doi/abs/10.1080/00201740500241847

Idealism and the Philosophy of Mind, D'ORO G, Inquiry 48(5):395-412 Oct 2005

semantically between the concept of an action and that of an event is a precondition for identifying a particular occurrence as an instance of either one or the other. Collingwood (1929) makes this point in his Lectures on Moral Philosophy where he claims that whereas a geologist can teach the distinction between sedimentary and crystalline rocks by pointing to instances of each, the moral philosopher cannot teach the distinction between the principle of duty and that of utility by pointing to dutiful actions and prudential actions because an action which is carried out for prudential considerations could also illustrate the principle of duty. The action/event distinction is rather like the distinction between the principle of duty and of utility. It is a distinction to which there corresponds no empirical difference. ${ }^{16}$ It is because the concepts of action and of event are not empirical but meta-level concepts that it is possible for the domain of enquiry of the sciences of mind and nature to overlap and for action and event explanations to be true of the same particulars in space and time. To illustrate this point Collingwood cites Aristotle's formula of the overlap of classes according to which "two concepts 'are the same thing' in the sense that a thing which exemplifies the one exemplifies the other also, but 'their being is not the same' in the sense that being an instance of the one is not the same as being an instance of the other" (EPM, 50). In one sense of "being", actions and events are the same thing; in another sense of being, they are not. They are the same because they overlap extensionally. They are not the same because they are intensionally distinct, because we mean different things when we characterise an occurrence as an action and when we characterise it as an event. The problem of explanatory exclusion, for Collingwood, arises only if one construes the action/event distinction as an empirical 
This is a preprint of an article submitted for consideration in the Inquiry @ 2005 [copyright Taylor \& Francis]; Inquiry is available online at: www.tandfonline.com http://tandfprod.literatumonline.com/doi/abs/10.1080/00201740500241847

Idealism and the Philosophy of Mind, D'ORO G, Inquiry 48(5):395-412 Oct 2005

classification. Once the action/event distinction is construed as an empirical classification, it becomes impossible to understand how different sciences can study the same things, i.e. the same particulars, whilst having very different subject matters or domains of enquiry.

But can Collingwood's conceptual idealism really succeed in defending an alternative to Kant's transcendental idealism and Davidson's anomalous monism? In other words, can Collingwood's conceptual idealism avoid the Kantian strategy of relegating the causal efficacy of practical reasons to the noumenal world, without facing the objection of epiphenomenalism that is so often raised against Davidson's attempt to defend the autonomy of the mental in the context of a monistic ontology?

One reason to suspect that Collingwood may be unable to evade the epiphenomenalist objection raised against Davidson is that in the reasons/causes debate prior to Davidson's 1963 paper ${ }^{17}$ it was customary to defend the autonomy of action from event explanations by claiming that the former, unlike the latter, are ex post facto rationalisations that yield no predictions (or retrodictions). It was assumed that if action explanations could yield predictions, there would be no difference between the sciences of mind and nature. In turn, the view that action explanations differ from event explanations because they yield no predictions was based on a commitment to a Humean epistemology. In other words, the view that action explanations differ from event explanations because the latter have predictive power (and hence existential import) whereas the former do not, relied on locating the reasons/causes distinction on either side of the Humean fork. This is not Collingwood's strategy. The reasons/causes distinction, 
This is a preprint of an article submitted for consideration in the Inquiry @ 2005 [copyright Taylor \& Francis]; Inquiry is available online at: www.tandfonline.com http://tandfprod.literatumonline.com/doi/abs/10.1080/00201740500241847

Idealism and the Philosophy of Mind, D'ORO G, Inquiry 48(5):395-412 Oct 2005

for Collingwood, is not a Humean distinction between relations of ideas and matters of fact but (for lack of a better expression) a distinction of fundamental ontology, i.e. a distinction between concepts that determine a priori the subject matters of the sciences of nature and mind or, as he puts it in An Essay on Metaphysics, between different meanings of the term "cause".

To understand how Collingwood can avoid the twin dangers of explanatory exclusion and of epiphenomenalism we need to be clear about the exact nature of the conceptual idealism he seeks to defend. ${ }^{18}$ Like Davidson, Collingwood seeks to graft conceptual idealism (or pluralism) onto a monistic ontology. But unlike Davidson Collingwood is not a physicalist but a neutral monist. Let me elaborate on both the similarities and differences between Collingwood and Davidson's positions.

As we have seen, both Davidson and Collingwood believe that there are key methodological differences between the sciences of nature and mind. ${ }^{19}$ This is what they have in common. But whereas Davidson belongs to a Lockean tradition which sees philosophy as the under-labourer of science and consequently believes its task to be that of explaining how such methodological distinctions can be reconciled with the ontology of natural science, Collingwood belongs to a Kantian tradition which sees philosophy as providing a second-order reflection upon first order knowledge and as offering a metalevel perspective from which to view natural science. As such Collingwood views the task of philosophy to be not that of showing how the action/event distinction may be reconciled with a scientific world view, but rather that of showing how incompatible descriptions of reality are possible in the first place. It is this key difference in their 
This is a preprint of an article submitted for consideration in the Inquiry @ 2005 [copyright Taylor \& Francis]; Inquiry is available online at: www.tandfonline.com http://tandfprod.literatumonline.com/doi/abs/10.1080/00201740500241847

Idealism and the Philosophy of Mind, D'ORO G, Inquiry 48(5):395-412 Oct 2005

respective conceptions of the task of philosophy that leads Davidson to opt for a layered view of science in which action explanations supervene upon event explanations and which instead leads Collingwood to opt for a bifurcated view of science in which action and event explanations articulate alternative conceptions of reality. The crucial difference here is that whereas in Davidson's anomalous monism there is one conception of reality, the one in which the relata of an explanation are connected causally rather than rationally, which has ontological priority, in Collingwood's neutral monism no conception of reality enjoys ontological pre-eminence. Davidson's granting of ontological primacy to event explanations leads him to believe that Alexander's principle, according to which "to be is to have causal powers", applies to what occurs only in so far as it is described as an event or, to use the terminology of An Essay on Metaphysics, it leads to the belief that Alexander's principle applies only to one sense of causation, the sense of causation employed in the natural sciences. Having hypostatised causation in a single sense Davidson is then forced to claim that if reasons are to have ontological or existential import they must be re-described as events. And having claimed this he then has to face the epiphenomenalist objection: "if reasons must be re-described as events in order to have causal efficacy they must remain epiphenomenal qua reasons". Collingwood's position is not vulnerable to the charge of epiphenomenalism because the problem of epiphenomenalism arises from the espousal of a layered view of science in which the bottom layer determines one's ontological commitments. Since Collingwood is not wedded to this conception of science,${ }^{20}$ he does not inherit the problems associated with it. In fact, Collingwood explicitly condemns the layered view of science that underpins 
This is a preprint of an article submitted for consideration in the Inquiry @ 2005 [copyright Taylor \& Francis]; Inquiry is available online at: www.tandfonline.com http://tandfprod.literatumonline.com/doi/abs/10.1080/00201740500241847

Idealism and the Philosophy of Mind, D'ORO G, Inquiry 48(5):395-412 Oct 2005

anomalous monism as based on a logical error. Were he alive today he would probably respond to Davidson's hypostatization of one conception of reality, the one captured by event rather than action explanations, or by the sense of cause employed in natural science, by pointing out that "reality is not a class concept", ${ }^{21}$ and that to reify the explanatory framework of natural science is tantamount to overlooking 'the ontological difference' or conflating Being with beings. ${ }^{22}$

Collingwood's conceptual dualism does seem to provide an answer to the question "how is mental causation possible?" which genuinely sidesteps the most common problems that have cast doubt on the viability of non-reductive physicalism. It recommends itself to us on the grounds that it succeeds in doing justice to the common sense view that mind matters but without denying the aspiration of physics to provide a complete explanation of what happens. Why, then, is Collingwood's neo-Kantian solution such a neglected alternative in the philosophy of mind? The answer seems to be that, in line with a Kantian rather than Lockean conception of the task of philosophy, Collingwood does not hand over to science the right to fix our ontological commitments. It is to these considerations that I turn in the next section.

\section{III}

Davidson's anomalous monism has rarely been challenged from an idealist standpoint. The most common criticism against it is levelled from the standpoint of physicalism and attempts to show that a consistent physicalism is incompatible with Davidson's nonreductivist aims. In the following I suggest that since the internal inconsistencies in the 
This is a preprint of an article submitted for consideration in the Inquiry @ 2005 [copyright Taylor \& Francis]; Inquiry is available online at: www.tandfonline.com http://tandfprod.literatumonline.com/doi/abs/10.1080/00201740500241847

Idealism and the Philosophy of Mind, D'ORO G, Inquiry 48(5):395-412 Oct 2005

position of anomalous monism do not, by themselves, provide overwhelming reasons for choosing (reductive) physicalism over (conceptual) idealism, the latter should not be dismissed purely on the grounds that it does not fit within a naturalistic world view.

Anomalous monism essentially involves three theses: (1) that mental events are causally related to physical events; (2) that singular causal relations are backed by strict laws and (3) that there are no strict psycho-physical laws. ${ }^{23}$ The reductivist seeks to show that anomalous monism is an impossible project because the concept of non-reductive physicalism is internally incoherent. This is the strategy followed by Kim whose philosophy provides an extended argument designed to expose the contradictions inherent in the idea of non-reductive physicalism. ${ }^{24} \mathrm{Kim}$ argues that anomalous monism endorses an insufficiently strong physicalist claim, i.e. that Davidson's monism is not uncompromisingly physicalist and that a satisfyingly robust form of physicalism is incompatible with Davidson's attempt to grant causal efficacy to the mental. Let us consider these two arguments in turn. Kim attacks Davidson's claim that anomalous monism is consistent with the claim that the mental supervenes or is dependent on the physical. As Davidson puts it "although the position I describe denies there are psychophysical laws, it is consistent with the view that mental characteristics are in some sense dependent, or supervenient, on physical characteristics. Such supervenience might be taken to mean that there cannot be two events alike in all physical respects but differing in some mental respect, or that an object cannot alter in some mental respect without altering in some physical respect". ${ }^{25}$ Kim shows that in order for supervenience to capture a relation of dependence of the mental on the physical, rather than mere 
This is a preprint of an article submitted for consideration in the Inquiry () 2005 [copyright Taylor \& Francis]; Inquiry is available online at: www.tandfonline.com http://tandfprod.literatumonline.com/doi/abs/10.1080/00201740500241847

Idealism and the Philosophy of Mind, D'ORO G, Inquiry 48(5):395-412 Oct 2005

covariation, one must give up premise (3) that there are no psycho-physical laws.

Psychophysical dependence, as opposed to co-variation, requires type physicalism, i.e. the acceptance of bridge laws, and hence reductivism. Kim's second argument is that the causal efficacy of the mental embedded in premise (1) violates the claim that physics can provide a complete explanation of reality. Reasons, for Kim, can be causally efficacious and still compatible with the demand for physicalist closure only to the extent that they are reduced to events, i.e. to the extent that they remain epiphenomenal qua reasons. A satisfyingly robust physicalism therefore requires one to relinquish premise (3) and to give an epiphenomenalist reading of premise (1), thereby abandoning Davidson's hopes of defending the autonomy of the mental within a naturalistic framework. ${ }^{26}$

Having argued that anomalous monism subscribes to a form of physicalism that is too weak to support the claim that the mental depends on the physical and that anomalous monism's commitment to the causal efficacy of the mental violates a satisfyingly robust form of physicalism, Kim urges us to endorse reductive physicalism as the only live option available to us today. But whereas his claim that anomalous monism is internally inconsistent is based on philosophical argument, his view that dualism of any kind, whether ontological or conceptual, is not a defensible contemporary option, is not. This is not to say that Kim's position is dogmatic in the sense that his preference for physicalism does not rest on evidence, but that the kind of evidence which seems to recommend the endorsement of reductive physicalism rather than conceptual idealism is evidence of an empirical rather than a priori nature ${ }^{27}$ Or else it would be difficult to understand why the failure of the non-reductivist project should automatically lead one to rule out conceptual 
This is a preprint of an article submitted for consideration in the Inquiry @ 2005 [copyright Taylor \& Francis]; Inquiry is available online at: www.tandfonline.com http://tandfprod.literatumonline.com/doi/abs/10.1080/00201740500241847

Idealism and the Philosophy of Mind, D'ORO G, Inquiry 48(5):395-412 Oct 2005

dualism as a dead end. Kim speaks from the perspective of someone who has already accepted the truth of physicalism on empirical grounds and who is consequently unwilling to test this fundamental commitment in a dialectical process in which one's initial premises may be reconsidered as a result of a priori reflection. In other words, Kim assumes that the method of natural science should fix our ontological commitments and is consequently unwilling to consider a solution (such as that offered by the conceptual idealist) which recommends itself not on empirical grounds, but on the basis of its ability to make sense of the perspective of common sense alongside the one of science.

Kim's efforts to demonstrate the incompatibility of physicalism and nonreductivism are intended to persuade the reader to abandon the latter rather than the former. But since he exposes the inconsistencies inherent in non-reductive physicalism by using the tools of immanent critique, his arguments can be lifted almost intact to conclude that, in order to pursue the non-reductivist project, one must relinquish physicalism. I am here assuming, of course, that the genuine philosophical issue at stake in debates concerning the nature of the mind and whether or not there is such a thing as an autonomous science of the mental, is not whether physicalism is true or false, but what it means and what endorsing it entails. In other words, I am presupposing that the philosophical issue at stake in the reductivism/non reductivism debate is not the truth of physicalism but its conceptual status, just as what was at stake in the free will $v s$ determinism debate was not the truth of either determinism or indeterminism but the issue of their compatibility or incompatibility. In fact, it is hard to see how else a philosophical argument could proceed, unless, of course, one were willing to assume that 
This is a preprint of an article submitted for consideration in the Inquiry @ 2005 [copyright Taylor \& Francis]; Inquiry is available online at: www.tandfonline.com http://tandfprod.literatumonline.com/doi/abs/10.1080/00201740500241847

Idealism and the Philosophy of Mind, D'ORO G, Inquiry 48(5):395-412 Oct 2005

philosophy is the mere under-labourer of science and that as such it ought simply to presuppose the truth of physicalism. ${ }^{28}$

In sum, the reductivist challenge, as articulated by Kim, confronts anomalous monism with the claim that a) the causal efficacy of the mental threatens the demand for physicalist closure and b) that token or non-reductive physicalism cannot account for a relation of psycho-physical dependence. The idealist does not disagree with such considerations but offers a different way forward. In a nutshell the idealist suggests that in order to deliver the goals of anomalous monism (i.e. to reconcile the claims of practical and theoretical reason) one ought to reinterpret premise (1) in methodological terms. Premise (1), as we have seen, concerns the causal efficacy of the mental. Davidson interprets the claim concerning the causal efficacy of the mental in quasi-Cartesian interactionist terms and in order to avoid the problem of causal over-determination by mental and physical causes suggests that reasons are causes only in so far as they are described as events. Then, when faced with the accusation of epiphenomenalism, he claims that "events cause other events no matter how they are described" ${ }^{29}$

Reinterpreting premise (1) in methodological terms, as the kind of idealism espoused by Collingwood requires, entails altering one's view of the nature of the relationship between actions and events and what is meant by the claim that "reasons are causes". For Davidson reasons are causes in the same way in which sheep are mammals, i.e. reasons are said to cause events in the way in which sheep are said to suckle their young, i.e. not in virtue of being sheep but in virtue of being mammals. For Collingwood, by contrast, the relationship between reasons and causes is a distinction between concepts 
This is a preprint of an article submitted for consideration in the Inquiry () 2005 [copyright Taylor \& Francis]; Inquiry is available online at: www.tandfonline.com http://tandfprod.literatumonline.com/doi/abs/10.1080/00201740500241847

Idealism and the Philosophy of Mind, D'ORO G, Inquiry 48(5):395-412 Oct 2005

or categories that determine a priori the kind of reality under consideration. Reasons may be said to be causes extensionally speaking (what is described as an event may also, under a different description, be an action), but reasons cannot be causes intensionally speaking because the concept of action is not a mark of the concept of event in the way in which being a sheep is part of the intension of the concept of mammal. This, I take it, is why Collingwood claims that the distinction between reasons and causes is a distinction between different meanings of the term "cause", or a distinction between higher-level concepts, rather than a distinction between subordinate and superordinate species.

Reinterpreting premise (1) in methodological terms and the reason/causes distinction as a distinction between meta-level concepts that determine a priori what kind of reality is under consideration involves abandoning the explanatory priority of physicalism without rejecting its aspiration to describe the whole of reality. This, it seems to me, is the distinctive advantage of the idealist solution over the reductivist one. If anomalous monism is inconsistent (and let us take this as given for the sake of argument), why should we turn to full-blown physicalism rather than idealism? Kim's answer seems to be that we should be physicalists because the method of natural science should fix our ontological commitments. But there does not seem to be anything particularly philosophical about such an answer. The idealist's answer is to suggest that we should let the methods of the sciences of mind and nature determine their respective subject matter or regional ontology, i.e. their conception of reality. The advantage of such a solution is that it does justice both to the claims of practical reason, according to which mind matters, and to the claims of theoretical reason, according to which there is a complete 
This is a preprint of an article submitted for consideration in the Inquiry @ 2005 [copyright Taylor \& Francis]; Inquiry is available online at: www.tandfonline.com http://tandfprod.literatumonline.com/doi/abs/10.1080/00201740500241847

Idealism and the Philosophy of Mind, D'ORO G, Inquiry 48(5):395-412 Oct 2005

physical explanation for everything that occurs. The idealist solution accommodates the claims of practical and theoretical reason in a way that reductivism will never be able to do. Idealism therefore recommends this solution to us on the grounds that it succeeds in making sense both of the folk-psychological view that mind matters, and of natural science's claim to explanatory completeness. This seems to be a good philosophical reason for endorsing the idealist alternative, whatever else one might think about it.

Collingwood's alternative should therefore be of interest to those who believe that there is an autonomous science of the mind in the strong sense outlined by Davidson rather than in the weak sense advocated by functionalists, but who also remain unconvinced that Davison's anomalous monism has the conceptual resources to defend the irreducibility thesis. Of course, one will choose to pursue the non-reductivist, rather than the naturalist agenda, only to the extent that one acknowledges the force of Davidson's point about the normativity of the mental. It is those who construe the concept of the autonomy of the mental in the strong sense implied by anomalous monism rather than in the weak sense implied by functionalism that should take Collingwood's neglected alternative seriously. Taking the latter seriously would also broaden considerably the domain of enquiry of what currently goes under the name of a philosophy of mind. Since the 1950s the philosophy of mind has been identified with a rather narrow set of assumptions within the philosophy of mind itself. It is perhaps time to broaden that subject matter and to acknowledge that the kind of conceptual idealism defended here is indeed a live option for us today. 
This is a preprint of an article submitted for consideration in the Inquiry @ 2005 [copyright Taylor \& Francis]; Inquiry is available online at: www.tandfonline.com http://tandfprod.literatumonline.com/doi/abs/10.1080/00201740500241847

Idealism and the Philosophy of Mind, D'ORO G, Inquiry 48(5):395-412 Oct 2005

\section{REFERENCES}

Baker, L. R. (1993) “Metaphysics and Mental Causation” in Heil, J. and Mele, A., (Eds.), Mental Causation, pp. 75-96 (Oxford: Oxford Clarendon Press).

Burge, T. (1993) "Mind-Body Causation and Explanatory Practice" in Heil, J. and Mele, A., (Eds.), Mental Causation, pp. 97-120 (Oxford: Oxford Clarendon Press).

Collingwood, R.G. (1929) “Lectures on Moral Philosophy”, Introduction, Bodleian Library, Collingwood Dep. 10.

Collingwood, R.G. (1933) An Essay on Philosophical Method (Oxford: Oxford Clarendon Press).

Collingwood, R.G. "Method and Metaphysics" in James Connelly and Giuseppina D'Oro (Eds.) (2005).

Collingwood, R.G. (1940) An Essay on Metaphysics (Oxford: Oxford Clarendon Press)

Connelly, J. and D’Oro G. (Eds.) (2005) An Essay on Philosophical Method (Oxford: Oxford Clarendon Press).

Crane, T. (2001) Elements of Mind (Oxford: Oxford University Press).

Davidon, D. [1963] (1980) “Actions, Reasons and Causes” in Davidson, D. Essays on Actions and Events, pp. 3-20 (Oxford and New York: Oxford University Press).

Davidson, D. [1970] (1980) “Mental Events” in Davidson's Essays on Actions and Events, pp. 207-224 (Oxford: Oxford University Press).

Davidson, D. (1993) “Thinking Causes” in J. Heil and A. Mele (Eds.) Mental Causation, pp. 3-17 (Oxford: Oxford Clarendon Press). 
This is a preprint of an article submitted for consideration in the Inquiry @ 2005 [copyright Taylor \& Francis]; Inquiry is available online at: www.tandfonline.com http://tandfprod.literatumonline.com/doi/abs/10.1080/00201740500241847

Idealism and the Philosophy of Mind, D'ORO G, Inquiry 48(5):395-412 Oct 2005

D’Oro, G. (2002) Collingwood and the Metaphysics of Experience (London and New

York: Routledge).

D’Oro, G., (2004) “Apriority and Philosophical Analysis”, Science et Esprit, 56, pp. 247263.

D’Oro, G. "Collingwood's 'Solution' to the Problem of Mind-Body Dualism”, forthcoming in Philosophia, 32, pp. 349-368.

D’Oro, G., "In Defence of the Agent Centred Perspective", forthcoming in Metaphilosophy 36.

Dray, W. H. (1957) Laws and Explanation in History (London: Oxford University Press).

Dray, W. H., (1980) "R. G. Collingwood and the Understanding of Actions in History" in his Perspectives on History, pp. 9-26 (London: Routledge and Kegan Paul).

Feigl, H. (1958) “The 'Mental' and the 'Physical”', in H. Feigl, G. Maxwell and M.

Scriven (Eds.), Minnesota Studies in the Philosophy of Science, Vol. 2, (Minneapolis: University of Minnesota Press).

Fodor, J. (1974) "Special Sciences, or the Disunity of Science as a Working Hypothesis", Synthese, 28, pp. 97-115.

Hempel, C. (1942) "The Function of General Laws in History”, Journal of Philosophy, 39, pp. 35-48.

Honderich, T. (1982) “The Argument for Anomalous Monism”, Analysis, 42, pp. 59-64.

Honderich, T. (1984) "Smith the Champion of Mauve", Analysis, 44, pp. 86-87.

Hutto, D. (1998a) “Davidson's Identity Crisis”, Dialectica, 52.

Hutto, D. (1998b) “Bradleyan Metaphysics: A Healthy Scepticism”, Bradley Studies, 4/1. 
This is a preprint of an article submitted for consideration in the Inquiry @ 2005 [copyright Taylor \& Francis]; Inquiry is available online at: www.tandfonline.com http://tandfprod.literatumonline.com/doi/abs/10.1080/00201740500241847

Idealism and the Philosophy of Mind, D'ORO G, Inquiry 48(5):395-412 Oct 2005

Hutto, D., (1998c) “An Ideal Solution to the Problems of Consciousness”, Journal of

Consciousness Studies, 5/3, pp. 328-43.

Kim, J. (1990) "Explanatory Exclusion and the Problem of Mental Causation", in E.

Villanueva (Ed.) Information, Semantics and Epistemology, (Cambridge Massachussets:

Basil Blackwell).

Kim, J. (1995a) "Multiple Realization and the Metaphysics of Reduction" in his

Supervenience and the Mind, pp. 309-335 (Cambridge: Cambridge University Press).

Kim, J. [1989] (1995b) “The Myth of Nonreductive Materialism” in his Supervenience

and the Mind, pp. 265-284 (Cambridge: Cambridge University Press).

Kim, J. (1995c) “The Nonreductivist's Troubles with Mental Causation” in

Supervenience and the Mind, pp. 336-357 (Cambridge: Cambridge University Press).

Kim, J. (1998) Mind in A Physical World (Cambridge: MIT Press/Bradford Books).

Marras, A. (1997) "Metaphysical Foundations of Actions Explanations" in Holstrom-

Hintikka, G. and Tuomela, R. (Eds.), Contemporary Action Theory, Vol. I, pp. 45-64

(Dordrecht: Kluwer Academic Publishers).

Papineau, D. (1995) “The Rise of Physicalism” in M. W. F. Stone and Jonathan Wolff

(eds.) The Proper Ambition of Science, (London and New York: Routledge).

Putnam, H. (1975) “The Nature of Mental States”, in H. Putnam (ed.), Collected Papers

II, (Cambridge: Cambridge University Press).

Ryle, G. (1949) The Concept of Mind (London: Hutchingson).

Sehon, S. (1997) "Deviant Causal Chains and the Irreducibility of Teleological

Explanation" Pacific Philosophical Quarterly, 78, pp. 195-213. 
This is a preprint of an article submitted for consideration in the Inquiry @ 2005 [copyright Taylor \& Francis]; Inquiry is available online at: www.tandfonline.com http://tandfprod.literatumonline.com/doi/abs/10.1080/00201740500241847

Idealism and the Philosophy of Mind, D'ORO G, Inquiry 48(5):395-412 Oct 2005

Sehon, S. (2000) “An Argument against the Causal Theory of Action” Philosophy and

Phenomenological Research, 60, pp. 67-85.

Smart, J.J.C. (1959) “Sensations and Brain Processes”, Philosophical Review, 68, pp. 141-156.

Sosa, E. (1984) “Mind-Body Interaction and Supervenient Causation”, Midwest Studies in Philosophy, IX, pp. 271-281

Sosa, E., (1993) “Davidson's Thinking Causes” in J. Heil and A. Mele (Eds.) Mental

Causation, pp. 41-50 (Oxford: Oxford Clarendon Press).

\footnotetext{
${ }^{1}$ I would like to thank the anonymous referees of Inquiry for their helpful suggestions.

${ }^{2}$ Fodor, J. (1974) mobilises these considerations in support of an argument for the autonomy of special sciences such as psychology, sociology and economics.

${ }^{3}$ The "must" here is a transcendental must.

${ }^{4}$ J. Kim (1995a) has convincingly argued that, at most, multiple realisation functionalism threatens psychology's aspiration to be a methodologically autonomous science, not its aspiration to be scientific: the multiple realisation thesis espoused by functionalists entails only that inductive generalisations must be species specific, that the psychologist cannot extrapolate from one species to another, not that a scientific study of mental phenomena is impossible.

${ }^{5}$ The argument against methodological unity was a central issue in debates in the philosophy of social science in the 1950s and 60s. Since Davidson such arguments have been construed in metaphysical rather than in methodological terms and have generally been pursued within the context of the philosophy of mind rather than in that of the philosophy of social science.

${ }^{6}$ Davidson, D. [1970] (1980) “Mental Events”, p. 214
} 
This is a preprint of an article submitted for consideration in the Inquiry @ 2005 [copyright Taylor \& Francis]; Inquiry is available online at: www.tandfonline.com http://tandfprod.literatumonline.com/doi/abs/10.1080/00201740500241847

Idealism and the Philosophy of Mind, D'ORO G, Inquiry 48(5):395-412 Oct 2005

\footnotetext{
${ }^{7}$ For the epiphenomenalist objection see, Honderich, T. (1982) and (1984).

${ }^{8}$ For Collingwood the science of mind, like logic and morality, is a normative or, as he puts it, a “criteriological" science.

${ }^{9}$ I am here using the terms "regional ontology" and "subject matter" interchangeably to indicate that the distinction between regional ontologies is a distinction between domains of enquiry rather than a distinction between empirical classes.

${ }^{10}$ See Collingwood (1933) and (1940). For an account of Collingwood's conceptual idealism see D’Oro (2002).

${ }^{11}$ This methodological debate was exemplified by W.H. Dray's defence of the autonomy of rational explanations against C. Hempel's argument for methodological unity (Hempel 1942). See Dray (1957) and 1980)
}

${ }^{12}$ See Kim, J. (1998), p. 59 ff. Here Kim is thinking primarily of contemporary participants in this debate, such as Lynne Rudder Baker (1993) and Tyler Burge (1993), but it is clear that he would think such objections also apply to Collingwood's approach to the issue of mental causation.

${ }^{13}$ The autonomy of mentalistic explanations has recently been defended by Scott Sehon (2000) and (1997).

${ }^{14}$ See Crane, T. (2001) p. 60. Crane, like Kim, seems to have in mind both contemporary contributors to the debate about mental causation such as Lynne Rudder and Tyler Burge and supporters of the Collingwood-Dray thesis.

${ }^{15}$ Similar objections are also raised by Marras, A. (1997).

${ }^{16}$ For Collingwood's discussion of how non-empirical or meta-level concepts may allow for extensional equivalence or overlap in empirical classes see Collingwood (1933). For the purpose of this paper I have ignored the debate concerning the continuity or otherwise between An Essay on Philosophical Method and An Essay on Metaphysics. I have discussed the latter in D'Oro (2002) and in Connelly, J. and D'Oro, G. (2005).

17 “Actions, Reasons and Causes" reprinted in Davidson, D. Essays on Actions and Events, Oxford and New York, Oxford University Press, 1980. 
This is a preprint of an article submitted for consideration in the Inquiry @ 2005 [copyright Taylor \& Francis]; Inquiry is available online at: www.tandfonline.com http://tandfprod.literatumonline.com/doi/abs/10.1080/00201740500241847

Idealism and the Philosophy of Mind, D'ORO G, Inquiry 48(5):395-412 Oct 2005

${ }^{18}$ Support for the kind of idealist position in the philosophy of mind that I defend here via a reconstruction of Collingwood's work has been recently canvassed by D. Hutto. See Hutto (1998a), (1998b) and (1998c).

${ }^{19}$ I have explored the relationship between Collingwood's and Davidson's philosophy of mind in “Collingwood's 'Solution' to the Problem of Mind-Body Dualism”, forthcoming in Philosophia 32, pp. 349368.

${ }^{20}$ I explore further the relationship between Collingwood's and Davidson's conception of science in "In Defence of the Agent Centred Perspective", forthcoming in Metaphilosophy 36.

${ }^{21}$ R. G. Collingwood, “Method and Metaphysics” in James Connelly and Giuseppina D’Oro (Eds.) (2005), p. 330 .

${ }^{22}$ A point also made by Heidegger in Being and Time when he takes pains to distinguish "reality" from "the real".

${ }^{23}$ Davidson, D. (1993), p. 3.

${ }^{24}$ See Kim (1995b), (1995c) and (1998).

${ }^{25}$ D. Davidson, [1970] (1980) "Mental Events", p. 214.

${ }^{26}$ See Kim [1989] (1995b), Kim (1990); Kim (1995c). See also Sosa, E. (1984) and (1993).

${ }^{27}$ For an empirical argument in support of physicalism see D. Papineau (1995).

${ }^{28}$ I have argued elsewhere, in D'Oro (2004) and “In Defence of the Agent-Centred Perspective", forthcoming in Metaphilosophy 36, that a robust defence of the autonomy of the mental properly rests on a conception of philosophy as a kind of "first science" rather than as the underlabourer of science.

${ }^{29}$ Davidson, D. (1993) “Thinking Causes”, p. 6. 